\author{
Military Technical College \\ Cairo, Egypt
}

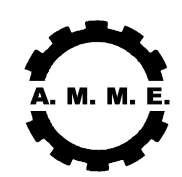

$12^{\text {th }}$ International Conference

on Applied Mechanics and

Mechanical Engineering (AMME)

\title{
HEAT TRANSFER ENHANCEMENT IN PIPE FLOW WITH DOWNSTREAM PULSATION
}

\author{
A.R. EL-Shamy*, R.I. Afify*, S.A. Abdel-Moneim* \\ and H.A. Refaey**
}

\begin{abstract}
Experiments were carried out to investigate the heat transfer characteristics for turbulent flow through pipes with downstream pulsation. Measurements were conducted in a horizontal brass pipe of $40 \mathrm{~mm}$ inner diameter and $3000 \mathrm{~mm}$ long under uniform heat flux condition, with air as a working fluid. The pulsating frequency was ranged from 45 to $145 \mathrm{~Hz}$ and Reynolds number was varied from 27900 to 58900. The results show that, an enhancement in heat transfer is obtained for the pulsated flow for different values of both Reynolds number and pulsation frequency. The rate of enhancement decreases as the pulsation frequency increases. The maximum enhancement of the relative average Nusselt number (about $84.5 \%$ ) is obtained with $\operatorname{Re}=55500$ and $\mathrm{f}=45 \mathrm{~Hz}$, while the minimum enhancement (about 17 $\%$ ) is obtained at $\operatorname{Re}=42500$ and $\mathrm{f}=145 \mathrm{~Hz}$. As Reynolds number increases from 27900 to 35800, the relative average Nusselt number increases and peaks at Reynolds of 35800 and pulsation frequency of 93.3. As Reynolds number increases further from 35800 to 42500 , a reduction in the relative average Nusselt number is obtained for the whole studied range of the pulsation frequencies. While as Reynolds number increases further $(42500 \leq \operatorname{Re} \leq 58900)$, the relative average Nusselt number increases again with about $84.5 \%$ maximum enhancement. The present experimental data for the relative average Nusselt number enhancement ratio were correlated in terms of Reynolds number and the dimensionless frequency.
\end{abstract}

KEYWORDS: pulsating pipe flow, downstream pulsation, flow vibration, pulsation frequency, periodic turbulent pipe flow.

\footnotetext{
* Mech. Eng. Dept., Shoubra Faculty of Engineering, Benha University

** Msc student
} 


\section{NOMONCLATURE}

SI units were used for the whole parameters within this paper.

\section{Symbols:}

A pipe cross-sectional area

$C_{p} \quad$ working fluid (air) specific heat

D inner diameter of the test-section

d rotating disk diameter

f pulsation frequency

h heat transfer coefficient

$k$ thermal conductivity of air

$\mathrm{L}$ tube length

$\mathrm{m}$ mass flow rate of air

$\mathrm{N}$ Revolutions per minute of rotating disk

$n$ number of holes in the rotating disk

$\mathrm{P}$ pressure

Q Total heat transfer rate

q" heat flux

$\mathrm{T}$ temperature

$U^{\star} \quad$ friction velocity, eq.(6)

$\mathrm{u}$ velocity

$\mathrm{X}$ axial distance from tube inlet

\section{Subscripts:}

avg average value

$f$ for fluid

in at tube inlet

$\mathrm{m}$ mean value

out at tube outlet

o,avg average value without pulsation

$p$,avg average value with pulsation

$p$ pulsation

$T$ total

w for tube inner surface

$x \quad$ local value

Dimensionless Terms:

$\mathrm{Nu}$ Nusselt number

$\mathrm{Pr} \quad$ Prandtl number

$\mathrm{Re}$ Reynolds number

Greek letters:

$\omega$ * angular frequency of pulsation

* dimensionless frequency, eq.(5)

$\mu \quad$ dynamic viscosity

$\rho$ density 


\section{INTRODUCTION}

Much attention has been given to the possibility of enhancing the heat transfer inside tubes which is one of the most important engineering applications. There are many different methods which create separation in the flow to enhance the heat transfer coefficient in internal flows. The pulsation is one of these methods, which exists in many applications such as internal combustion engines, refrigerating systems, reciprocating compressors, twin screw compressors, concentric tube heat exchanger. This flow separation creates regions of reverse flow where regions of high mixing and turbulence are generated. The boundaries of this reverse flow are characterized by creation and destruction of eddies of large turbulence energy and vortex shedding, which are expected to increase the heat transfer rates.

For the pulsating flow in pipes, many investigations have been performed in practical use and many theoretical and experimental results have been reported. Kita et al. [1] studied theoretically the effect of pulsation on heat transfer characteristics for a laminar flow in a pipe under constant surface temperature. The results showed that, the Nusselt number fluctuates with flow pulsation. The fluctuation of Nusselt number in pulsating flow was independent of Prandtl number but depends on both pulsation frequency and the amplitude. Krishnan and Sastri [2] studied experimentally the effect of pulsation on heat transfer coefficient for steam-water, double pipe heat exchanger. The pulsation was imposed to the water flow by a rotating ball valve, located upstream, connected to a variable speed motor. The pulsation frequency ranged from 0 to $7 \mathrm{~Hz}$. The results showed that the pulsation could be used as a method of augmenting the heat transfer in the heat exchanger with fluids of high Prandtl numbers for the laminar flow. The influence of pulsation on heat transfer in a uniformly heated channel with laminar fully developed pulsating flow was investigated analytically by Siegel [3]. The results showed that the heat transfer rate from the channel walls with uniform heat flux were reduced by pulsation. Liao and Wang [4] studied experimentally the effect of pulsation on heat transfer coefficient of fully developed and steady turbulent pulsating water flow in a stainless steel tube of 10.92 $\mathrm{mm}$ inner diameter and $1960 \mathrm{~mm}$ length. Flow pulsation was produced by an oscillator consisting of motor driver ball valve system located upstream of the flow. The results showed that, Nusselt number was reduced with pulsation and the magnitude of reduction mainly depends on the amplitude. Moschandreou and Zamir [5] investigated analytically the problem of pulsating flow in a tube with constant wall heat flux to determine how pulsation affects the rate of heat transfer and how the phenomenon depends on the Prandtl number and the pulsation frequency. The results indicate that, the increase in Nusselt number was inversely proportional to the Prandtl number. Guo and Sung [6] performed an analysis of the Nusselt number in laminar pulsation pipe flow, with uniform heat flux. The influence of the pulsation amplitude and frequency on heat transfer was studied. The results showed that, an improvement in Nusselt number was observed for the large amplitude of pulsation flow rate. Said et al. [7] investigated experimentally the effect of pulsation on heat transfer coefficient in the thermal entrance region of turbulent pulsating airflow in a pipe. The pipe wall was kept at uniform heat flux. Reynolds number was varied from 6000 to 42000 , while pulsation frequency ranged from 1 to $13 \mathrm{~Hz}$. The results showed an enhancement in the mean Nusselt number of about $9 \%$ at frequency of 2 $\mathrm{Hz}$ and Reynolds number of about 15000. The rate of enhancement of the mean Nusselt number decreased as Reynolds number increased. Endo and Iwamoto [8] performed an experimental and numerical study to get detailed information of noise 
generation from a pulsatile jet discharged from the end of a pipe, the flow field through the pipe and the flow field downstream of the pipe end. Zuo et al. [9] discussed the effect of pulsation motion on a heat pipe mechanism for cooling of high heat flux electronics. The investigation of pulsatile Newtonian fluid flow in circular rigid pipes was performed by Adamec et al. [10]. Heat transfer characteristics to turbulent pulsating pipe air flow under different conditions of Reynolds number and pulsation frequency were experimentally investigated by Zohir [11]. Uniform wall heat flux condition was considered. Reynolds number was varied from 8462 to 48543 , while the frequency of pulsation ranged from 1 to $29.5 \mathrm{~Hz}$. The results showed that, the relative mean Nusselt number was strongly affected by both pulsation frequency and Reynolds number. Heat transfer characteristics to laminar pulsating pipe flow under different conditions of Reynolds number and pulsation frequency were experimentally investigated by Habib et al. [12]. Reynolds number was varied from 780 to 1987 , while the frequency of pulsation ranged from 1 to $29.5 \mathrm{~Hz}$. The results showed that, the relative mean Nusselt number was strongly affected by pulsation frequency while it was slightly affected by Reynolds number. Said et al. [13] investigated numerically the flow and heat transfer characteristics of pulsating turbulent flow in an abrupt pipe expansion. It was found that, for all pulsation frequencies, the variation in the mean time-averaged Nusselt number, maximum Nusselt number and its location with Reynolds number and diameter ratio exhibit similar characteristics to steady flows. Hessami et al. [14] investigated experimentally the effect of pulsation on heat transfer with water flowing in a heated horizontal pipe. Experiments were performed for different values of pulsation frequency and amplitude, superimposed over a varying main flow rate through the pipe. An experimental study was carried out by $\mathrm{Yi}$ et al. [15] for the heat transfer characteristics and the flow patterns of the evaporator section using small diameter coiled pipes in a looped heat pipe (LHP). The results showed that, the combined effects of the evaporation of the thin liquid film, the disturbance caused by pulsation and the secondary flow, enhanced greatly the heat transfer and the critical heat flux of the evaporator section. Wu et al. [16] established a mathematical model based on the one-dimensional unsteady gas flow equations to describe the discharge pressure pulsation, which considers the effects of friction and heat transfer between the gas and the pipe. El-Shazly et al. [17] studied experimentally the heat transfer to an air pulsated flow downstream of an axisymmetric abrupt expansion in a circular pipe with constant wall heat flux. Runs were made with small diameter (d) to large diameter (D) ratios of $0.32,0.49$, and 0.61 . Reynolds number was varied from 7760 to 40084 and pulsation frequency ranged from 1 to $13 \mathrm{~Hz}$. The results showed that, the mean Nusselt number of sudden pipe expansion increases as the $d / D$ ratio decreases. Also, the mean Nusselt number was strongly affected by Reynolds number, while it was slightly affected by the pulsation frequency for any $d / D$ ratios.

On view of the survey of the previous work, the literature survey has brought conflicting conclusions as to the advantages or disadvantages of pulsation on heat transfer. Thus, the present research was initiated with a wide range of Reynolds number and pulsation frequencies. In the present work, experiments were carried out to investigate the heat transfer characteristics for turbulent flow through pipes with downstream pulsation. The pipe wall was kept at uniform heat flux. The pulsating frequency was ranged from 45 to $145 \mathrm{~Hz}$ and Reynolds number was varied from 27900 to 58900 . 


\section{EXPERIMENTAL APPARATUS}

An experimental set up was designed and constructed to make it available to carry out the present heat transfer measurements for turbulent air flow in pipe with downstream pulsation. It consists mainly of: air passage, test section, pulsation mechanism, and measuring instruments as shown in Fig.(1-a). A centrifugal type air blower, driven by an electric motor of $5.5 \mathrm{hp}$ capacity and $3000 \mathrm{rpm}$ normal speed, was used to supply the system with air at the required flow rate. The air flow rate can be controlled via the blower intake gate. The air flow rate was measured by a calibrated flow orifice meter and the readings of its head difference was indicated by a U-tube differential manometer. The test section was made of a horizontal circular brass tube of $40 \mathrm{~mm}$ inner diameter, $3.5 \mathrm{~mm}$ thickness and $3000 \mathrm{~mm}$ long. The test section was heated by means of an electric heater and to prevent heat loss, a guard heater was used as shown in Fig.(1-b).

Calibrated thermocouples made of copper-constantan wires of $0.5 \mathrm{~mm}$ diameter were used to measure the surface temperatures at seventeen different test locations distributed axially along the test-section wall with relatively high concentration at entrance. At each test location, two diametrically opposite top-bottom, thermocouples were fixed on the tube wall to check the axisymetry of the flow as shown in Fig.(1-c). In addition, four pairs of similar thermocouples were oppositely fixed at equal distance on the two sides of the asbestos layers which was inserted between the main and the guard heaters to give an indication about the thermal balance. The junctions of the thermocouples were embedded in holes of $2 \mathrm{~mm}$ diameter and 0.5 $\mathrm{mm}$ from the inner surface of the tube. The air flow temperature was measured via radiation shielded thermocouples mounted on vertical traverse mechanisms at tube inlet and exit, respectively. To avoid flow disturbance, each of the thermocouples probe with its shield was resided in a tubular cavity that was assembled normal to the test tube such that the probe was presented only in the flow field at the instant of reading.

The pulsation mechanism was located at the downstream end of the test tube. It was constructed of a variable speed motor (which has three main speeds of 1350,1400 , and $1450 \mathrm{rpm}$ ) and a rotary disk fixed on the motor spindle as shown in Fig.(1-d). Three wooden disks, each has $240 \mathrm{~mm}$ outer diameter, were used. The first disk has one hole of $40 \mathrm{~mm}$ diameter (as the same as the test tube inner diameter), the second disk has two holes 180 degree apart and the third disk has three holes 120 degree apart. The variable speed motor rotates the disks with the three different main speeds of 1350,1400 , and $1450 \mathrm{rpm}$. The variable speed motor was supported such that, the rotary disk is at $1.5 \mathrm{~mm}$ from the test tube and during rotation the disks holes becomes exactly in front of the test tube. Pulsation in the air stream was generated by the rotation of the disks at downstream end of the test tube. For each revolution of the variable speed motor, the flow was stopped and released by the disks holes. So, the pulsation mechanism could be adjusted to give different pulsation frequencies within the range of 45 to $145 \mathrm{~Hz}$.

The following measuring instrumentations were used to measure the corresponding different parameters:

1- A digital multi meter, with minimum readings of 0.1 Volt and $1 \mathrm{Ohm}$, was used to measure the voltage drop and the electric resistance for each of the main and guard heaters. 
2- A digital Thermometer, with minimum readings of $0.1^{\circ} \mathrm{C}$, was used to read the thermocouples signals

3- U-tube differential manometer, was used to measure the head difference between the two sides of the orifice meter to calculate the air flow rate.

4- A digital tachometer, was used to measure the revolutions per minute of the rotating disk to calculate the pulsation frequency.

5- Wet and dry bulb thermometers, with full scale of $50{ }^{\circ} \mathrm{C}$, and $0.2{ }^{\circ} \mathrm{C}$ division, were used to measure the lab air conditions.

\section{METHOD OF CALCULATIONS}

The test tube was divided into 16 segments with different axial lengths with high concentration at the entrance region. The local heat transfer coefficient for each tube segment was calculated simply by,

$$
h_{x}=\frac{q "}{T_{w, x}-T_{f, x}}
$$

where,

q" is the heat flux, calculated from the readings of the main heater circuit (voltage, resistance and power factor) and the tube surface area.

$T_{w, x}$ is the local inner surface mean temperature of the tube segment (the mean value between the top and bottom thermocouples readings)

$T_{f, x}$ is the local flow mean temperature at the tube segment, calculated from the heat balance for each segment and checked with the mean value calculated by integrating the measured radial temperature profiles at tube inlet and exit, respectively.

The local Nusselt number based on the local heat transfer coefficient was calculated by,

$$
N u_{x}=\frac{h_{x} D}{k}
$$

and the average Nusselt number was calculated by averaging the local values as follows:

$$
\overline{N u}=\frac{1}{L} \int_{x=0}^{L} N u_{x} d x
$$

Also, the flow Reynolds number was calculated by,

$$
\operatorname{Re}=\frac{4 m}{D}
$$

The air properties that included within the calculated parameters were taken at an average temperature of $\left(\mathrm{T}_{\text {in }}+\mathrm{T}_{\text {out }}\right) / 2$.

The Dimensionless frequency, as listed in [7] was calculated according to the following equation: 


$$
{ }^{*}=\frac{D}{U^{*}}
$$

where,

is the angular frequency of pulsation, $f$

$\mathrm{f}$ is the pulsation frequency, $\mathrm{f}=(2 \mathrm{~N} / 60), \mathrm{Hz}$

$\mathrm{N}$ is the revolutions per minute of the rotating disk

$\mathrm{n}$ is the number of holes in the disk

$\mathrm{U}^{*}$ is the friction velocity, which is listed in White [18] as,

$$
\mathrm{U}^{*}=\frac{0.199 u_{m}}{\operatorname{Re}^{0.125}}
$$

An uncertainty analysis was conducted to determine the overall error in the calculated heat transfer coefficient due to uncertainties in the measurements of voltage drop, electric resistance, heating surface area, surface and flow mean temperatures. This was accomplished by applying the differential approach and a total of $1.5 \%$ average uncertainty in the heat transfer coefficient was found.

\section{RESULTS AND DISCUSSION}

A preliminary series of experiments was carried out for the case of pipe flow without pulsation to check the validity of the present set up and the measuring instruments. The present results of the local Nusselt number for pipeflow without pulsation at different Reynolds numbers are shown in Fig.(2). The present results for the average Nusselt number for non-pulsated pipe flow were obtained and compared with the previously published correlations ( Dittus-Boelter and Colburn cited in [19] ) and a maximum deviation of $\pm 9 \%$ within a range of Reynolds number from $27 \times 10^{3}$ to $59 \times 10^{3}$ was found as shown in Fig.(3). Thus, it can be concluded that the present experimental apparatus and the measuring instruments are reasonable to carry out the required experiments for pipe flow with downstream pulsation.

The influence of the imposed frequency of pulsation on the heat transfer, for turbulent pulsating flow inside the test section under uniform heat flux is shown in Fig.(4). A significant enhancement in the local Nusselt number along the test section for the tested range of pulsation frequencies ranged from 45 to $145 \mathrm{~Hz}$ at different Reynolds numbers is obtained. The results of the local Nusselt number for flow with downstream pulsation at different Reynolds numbers varied from 27900 to 58900 with different pulsation frequencies are presented in Fig.(5). The results show that the local Nusselt number values for the pulsated flow increases with Reynolds number and decreases with the pulsation frequencies for the tested range of different parameters.

The effects of both pulsation frequency and Reynolds number on heat transfer are discussed in terms of the relative average Nusselt number of pulsated flow $\left(\mathrm{Nu}_{\mathrm{p}, \mathrm{avg}} /\right.$ $\mathrm{Nu}_{0, \text { avg }}$ ). Figure (6) shows the variation of the relative average Nusselt number with the pulsation frequency ranged from 45 to $145 \mathrm{~Hz}$ at different Reynolds numbers. It can be seen that, an enhancement in heat transfer is obtained for the pulsated flow for different values of both Reynolds number and pulsation frequency. The rate of enhancement decreases as the pulsation frequency increases. For $(27900 \leq \operatorname{Re} \leq$ $35800)$ and frequency of $(45 \leq f \leq 96.7 \mathrm{~Hz})$, the relative average Nusselt number 
firstly increase slightly with maximum enhancement of about $64 \%$ obtained at Reynolds number of 35800 and frequency 93.3 of $\mathrm{Hz}$ and then decreases again with frequency. The maximum enhancement of the relative average Nusselt number (about $84.5 \%$ ) is obtained with $\operatorname{Re}=55500$ and $\mathrm{f}=45 \mathrm{~Hz}$, while the minimum enhancement ( about $17 \%$ ) is obtained at $R e=42500$ and $f=145 \mathrm{~Hz}$. The influence of Reynolds number on the relative average Nusselt number for pulsation frequencies of $(45 \leq f \leq 145 \mathrm{~Hz})$ is shown in Fig.(7). As Reynolds number increases from 27900 to 35800 , the relative average Nusselt number increases and peaks at Reynolds of 35800 and pulsation frequency of 93.3. As Reynolds number increases further from 35800 to 42500 , a reduction in the relative average Nusselt number is obtained for the whole studied range of the pulsation frequencies. While as Reynolds number increases further $(42500 \leq \operatorname{Re} \leq 58900)$, the relative average Nusselt number increases again with about $84.5 \%$ maximum enhancement obtained at $\operatorname{Re}=55500$ and $\mathrm{f}=45 \mathrm{~Hz}$. The enhancement in the relative average Nusselt number which is obtained at $27900 \leq \operatorname{Re} \leq 58900$ and $45 \leq f \leq 145 \mathrm{~Hz}$ may be attributed to many effective parameters, such as, increase in level of turbulence due to pulsation, forced circulation which is introduced in the boundary layer due to pulsation and the interaction between the turbulent bursting frequency and the imposed pulsation frequency. If the flow pulse frequency is close to the frequency with which the viscous sub- layer is renewed, bursting frequency, a certain resonance interaction may occur. This interaction affects the heat transfer characteristics and leads to an increase or decrease in the heat transfer rate. The results of the relative average Nusselt number for the turbulent pulsating flow are plotted in terms of the dimensionless frequency as shown in Fig.(8). For Reynolds number (27900 $\leq \operatorname{Re} \leq$ $42500)$, the relative average Nusselt number firstly increase and peaks at a certain dimensionless frequency and then decreases again with *. For Reynolds number (51500 $\leq \operatorname{Re} \leq 58900)$, a maximum enhancement is obtained at dimensionless frequency of 4.56 and $\operatorname{Re}$ of 55500 .

The present experimental data for the relative average Nusselt number enhancement ratio was correlated in terms of Reynolds number and dimensionless frequency and the following correlation was obtained:

$$
\left(\mathrm{Nu}_{\mathrm{p}, \text { avg }} / \mathrm{Nu} \mathrm{o}_{\mathrm{avg}}\right)=\mathrm{a} \omega^{\star 3}+\mathrm{b}^{\star 2}+\mathrm{c} \quad{ }^{*}+\mathrm{d}
$$

where,

$a, b, c$, and d are functions of Reynolds number;

$$
\begin{aligned}
& a=-\left(7.523 \times 10^{-8} \mathrm{Re}\right)+1.841 \times 10^{-3}, \\
& b=\left(1.586 \times 10^{-6} \mathrm{Re}\right)-0.0234 \text {, } \\
& c=-\left(8.5835 \times 10^{-6} \mathrm{Re}\right)-0.1049 \text {, } \\
& \text { and } d=\left(1.5056 \times 10^{-5} \mathrm{Re}\right)+2.44
\end{aligned}
$$

The present correlation is valid within $\pm 17.2 \%$ maximum deviation for the present experimental data within the investigated range of Reynolds number from 27900 to 58900 and the dimensionless frequency ranged from 4 to 26 . The results of the relative average Nusselt number of Zohir [11] for turbulent pulsating pipe flow are displayed in Fig.(8-a) for comparison with the present results and a similar trend was observed. In fact, the difference between the results is due to many parameters such as , the type of the pulsator and its location and the different ranges of the studied parameters. 


\section{CONCLUSIONS}

Heat transfer characteristics for turbulent flow through pipes with downstream pulsation have been investigated experimentally. The pulsating frequency was ranged from 45 to $145 \mathrm{~Hz}$ and Reynolds number was varied from 27900 to 58900 . The experimental results suggest the following conclusions:

1- The relative average Nusselt number is dependent on both frequency of pulsation and frequency of turbulence (bursting frequency).

2- A significant effect on heat transfer has been obtained, when the frequency of pulsation is very close to the turbulence bursting frequency, where resonance interaction between them can occur.

3- There is a fluctuation in the enhancement of the heat transfer for the turbulent pulsating flow as it depends on many parameters. These parameters are Reynolds number, imposed pulsation frequency and turbulent bursting frequency, that associated with turbulent flow.

4- The rate of enhancement decreases with the pulsation frequency and increases with Reynolds number.

5- The maximum enhancement of about $84.5 \%$ in the relative average Nusselt number is obtained at ${ }^{*}$ of 4.56 and $\operatorname{Re}$ of 55500 , where interaction between bursting frequency and pulsation frequency may occur.

6- The minimum enhancement of about $17 \%$ is obtained at * of 18.14 and $\operatorname{Re}$ of 42500.

7- An empirical correlation is obtained for the influence of Reynolds number and pulsation frequency on the relative average Nusselt number.

\section{REFERANCES}

[1] Kita, Y., Hayashi, T., and Hirose, K., "Heat Transfer in Pulsating Laminar Flow in a Pipe", Bulletin of the JSME, Vol. 25, No. 200, pp. 217-224, (1982).

[2] Krishnan, K. N., and Sastri, V. M. K., "Pulsating Flows of Fluids with Temperature Dependent Viscosities", Heat and Mass Transfer/Waerme and Stoffuebertragung, Vol. 24, pp. 37-42, (1982).

[3] Siegel, R., "Influence of Oscillation on Heat Transfer in a Uniformly Heated Channel", Journal of Heat Transfer, Vol. 109, pp. 244-247, (1987).

[4] Liao, M. S., and Wang C. C., "An Investigation of Heat Transfer in Pulsating Turbulent Pipe Flow", ASME, Fundamentals of Forced and Mixed Convection, HTD, Vol. 42, pp. 53-60, (1988).

[5] Moschandreou, T., and Zamir, M., "Heat Transfer in a Tube with Pulsating Flow and Constant Heat Flux", Int. J. of Heat and Mass Transfer, Vol. 40, No. 10, pp. 2461- 2466, (1997).

[6] Guo, Z., and Sung, H. J., "Analysis of the Nusselt Number in Pulsating Pipes Flow", Int. J. of Heat and Mass Transfer, Vol. 40, No.10, pp. 2486-2489, (1997).

[7] Said, S.A.M., Al-Farayedhi, A.A., Habib, M.A., Gbadebo, S. A., Asghar, A., and Al-Dini, S.A., "Experimental Investigation of Heat Transfer in Pulsating Turbulent Pipe Flow", $2^{\text {nd }}$ International conference on turbulent heat transfer, (1998).

[8] Endo, M., and Iwamoto, J., "Numerical Analysis of Pulsatile Jet from Exhaust Pipe", JSAE -Review, Vol. 20, No. 2, pp. 243-249, (1999). 
[9] Zuo, Z. J. , North, M. T., and Ray, L. , "Combined Pulsating and Capillary Heat Pipe Mechanism for Cooling of High Heat Flux Electronics", ASME, HTD , Vol. 364, No. 4, pp. 237-243, (1999).

[10] Adamec, J., Nozicka, J., and Korenar, J, "Investigation of the Pulsatile Pipe Flow" Heat \& Technology, Vol. 18, No. 2, pp 17-22, (2000).

[11] Zohir, A.E., "An Experimental Investigation of Heat Transfer to Laminar and Turbulent Pulsating Pipe Flow", Ph.D. Thesis, Cairo University, (2000).

[12] Habib, M. A., Attya, A. M., Eid, A. I., and Aly, A. Z ., "Convective Heat Transfer Characteristics of Laminar Pulsating Pipe Air Flow", Heat \& Mass transfer I waerme und stoffuebertragung, Vol. 38, No. 3, pp. 221-232, (2002).

[13] Said, S. A. M., Habib, M. A., and lqbal, M. O., "Heat Transfer to Pulsating Turbulent Flow in an Abrupt Pipe Expansion", Int. J. of Numerical Methods for Heat \& Fluid Flow, Vol. 13, No. 2-3, pp. 286-308, (2003).

[14] Hessami, M. A., Berryman, A., and Bandopdhayay, P., "Heat Transfer Enhancement in an Electricity Heated Horizontal Pipe due to Flow Pulsation", ASME, HTD , Vol. 374, No. 3, pp. 49-56, (2003).

[15] Yi, J., Liu, Z. H., and Wang, J., "Heat Transfer Characteristics of the Evaporator Section using Small Helical Coiled Pipes in a Looped Heat Pipe" Applied Thermal Engineering, Vol. 23, No. 1, pp. 89-99, (2003).

[16] Wu, H., Xing, Z., Peng, X., and Shu, P., "Simulation of Discharge Pressure Pulsation within Twin Screw Compressors", Proceedings of the Institution of Mechanical Engineers, Part A, Journal of Power \& Energy, Vol. 218, No. 4, pp. 257-264, (2004).

[17] El-Shazly, K.M., Zohir, A.E., Abdel-Aziz, A.A, and Abdel-Mohimen, M., "Heat Transfer Characteristics of Pulsated Flow Downstream of Abrupt Expansion Through Pipes", $2^{\text {nd }}$ International Conference on Advances in Engineering Sciences \& Technologies, the National Research Centre, Cairo, Egypt, (2005).

[18] White, F.M., "Fluid Mechanics", McGraw-Hill, New York, (1979).

[19] Incropera, F.P. and DeWitt, D. P., "Fundamentals of Heat and Mass transfer," $3^{\text {rd }}$ ed., John wiley and Sons, New York, (1990). 


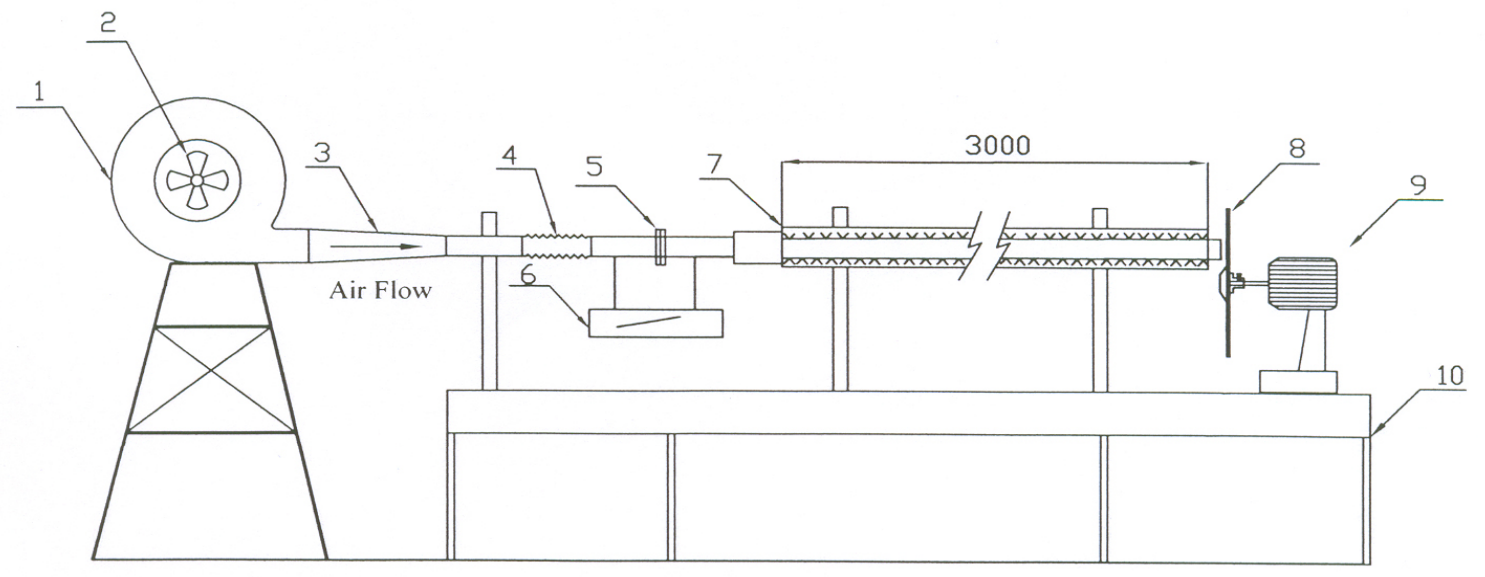
1- Air blower
2- Intake gate
5- Orifice meter
3- Conical section
4- Flexible Joint
8- Rotating disk
6- Manometer
7- Test section
9- Variable speed motor
10- Bench

(a) The test rig

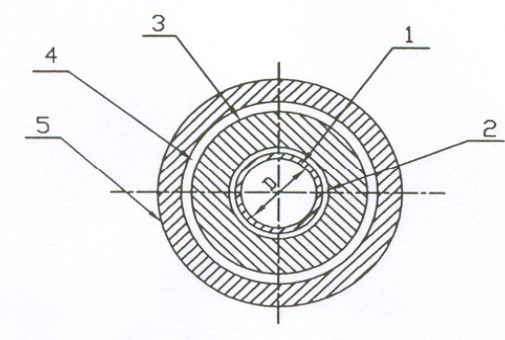

(b) Cross section in the test section

$$
\begin{aligned}
& \text { 1- Brass tube } \\
& 2 \text { - Main heater } \\
& \text { 3- Asbestos insulation } \\
& 4 \text { - Gaurd heater } \\
& 5 \text { - Outer asbestos insulation }
\end{aligned}
$$

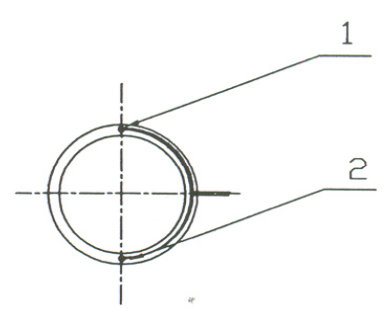

1- Top 2- Bottom

(c) Thermocouples fixation

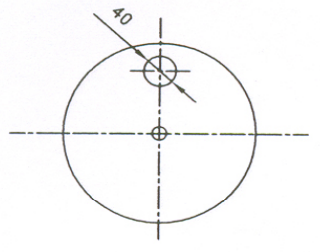

Single hole disk

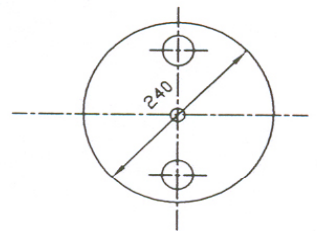

Two holes disk

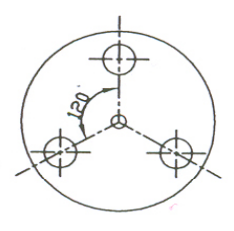

Three holes disk

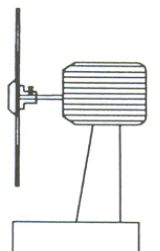

Variable speed motor

(d) Components of the pulsating mechanism

Dims in $\mathrm{mms}$

Fig.(1): The Experimental Apparatus 


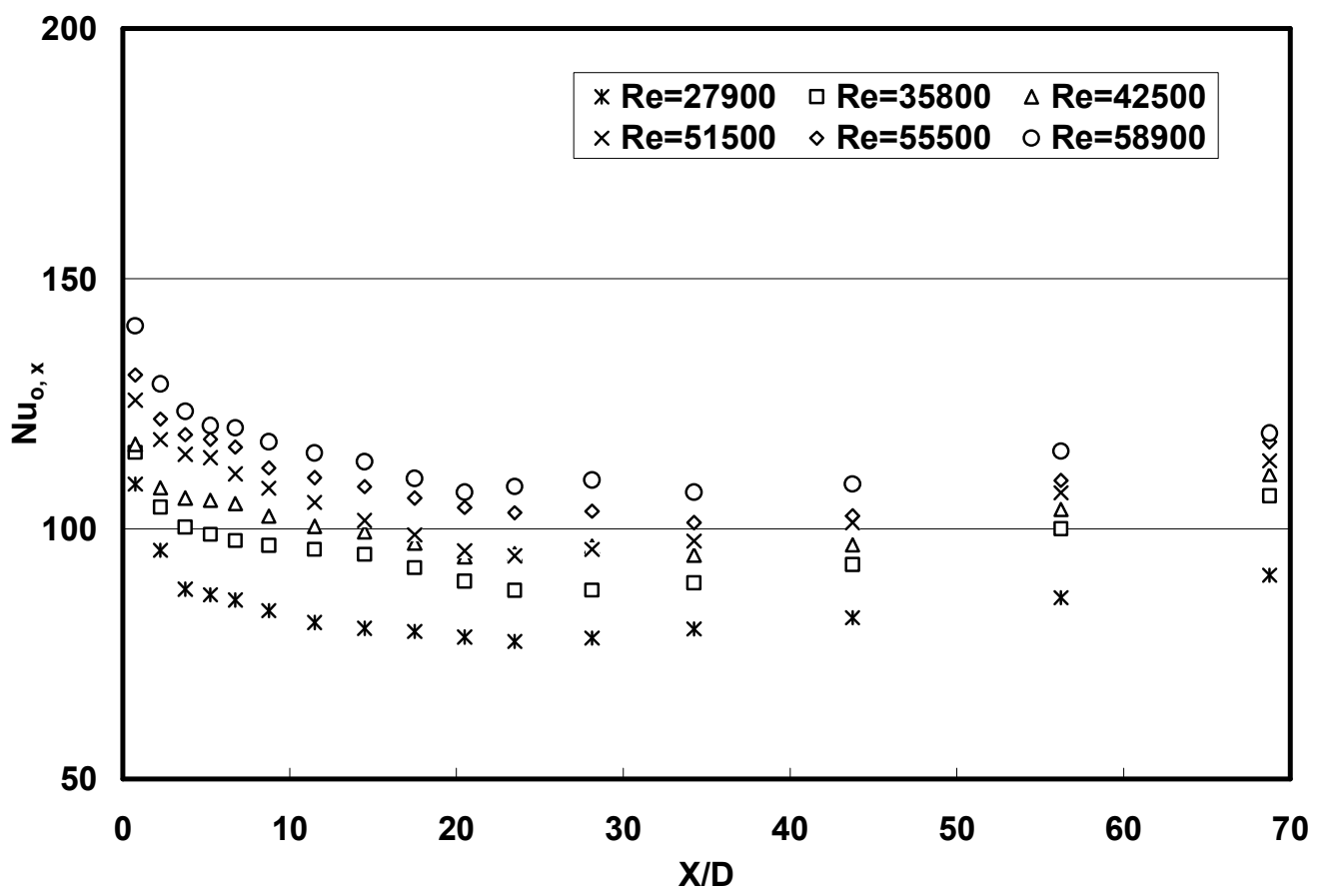

Fig.(2): Local Nusselt number at different Reynolds numbers for flow without pulsation

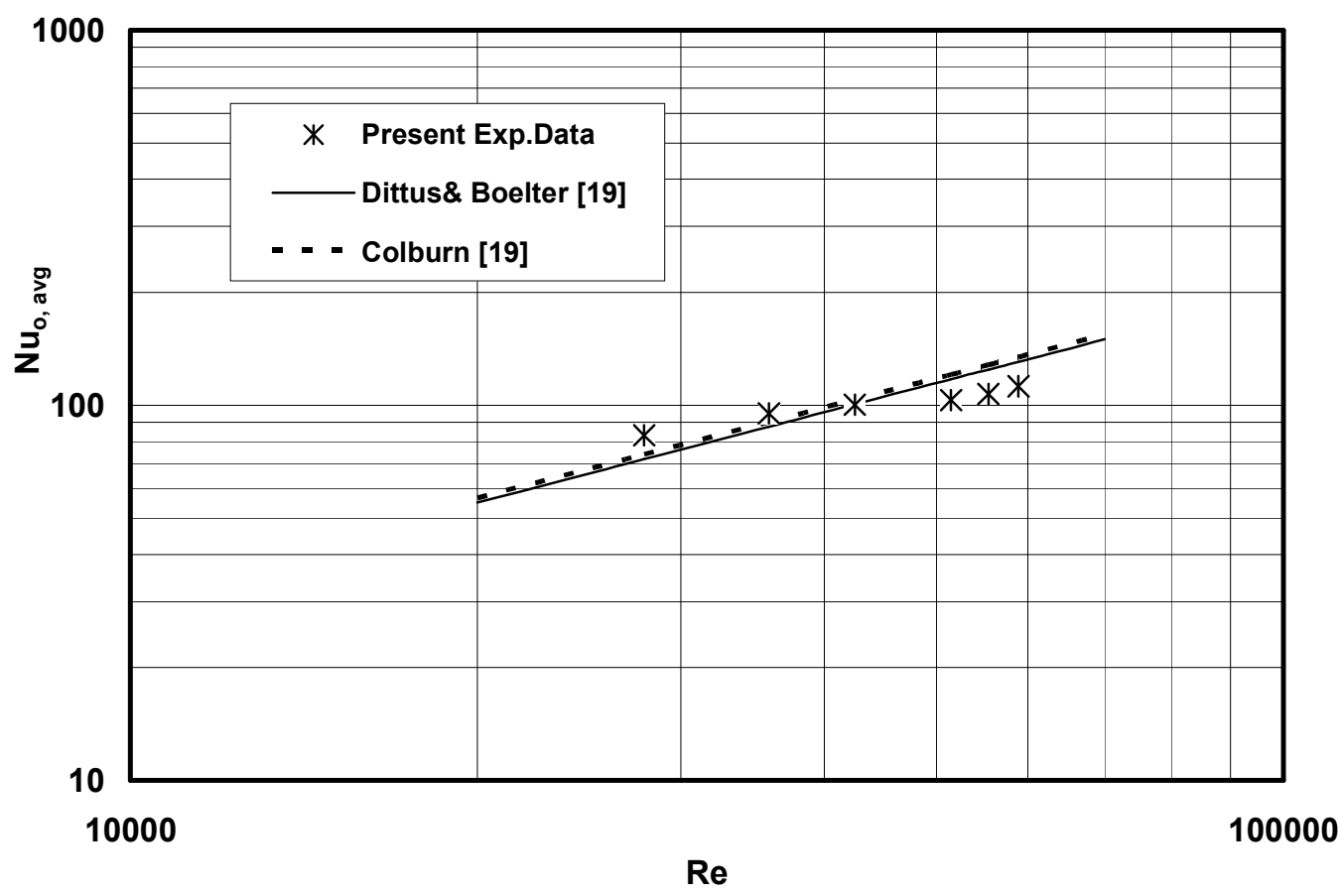

Fig.(3): Variation of the average Nusselt number with Reynolds number for flow without pulsation. 


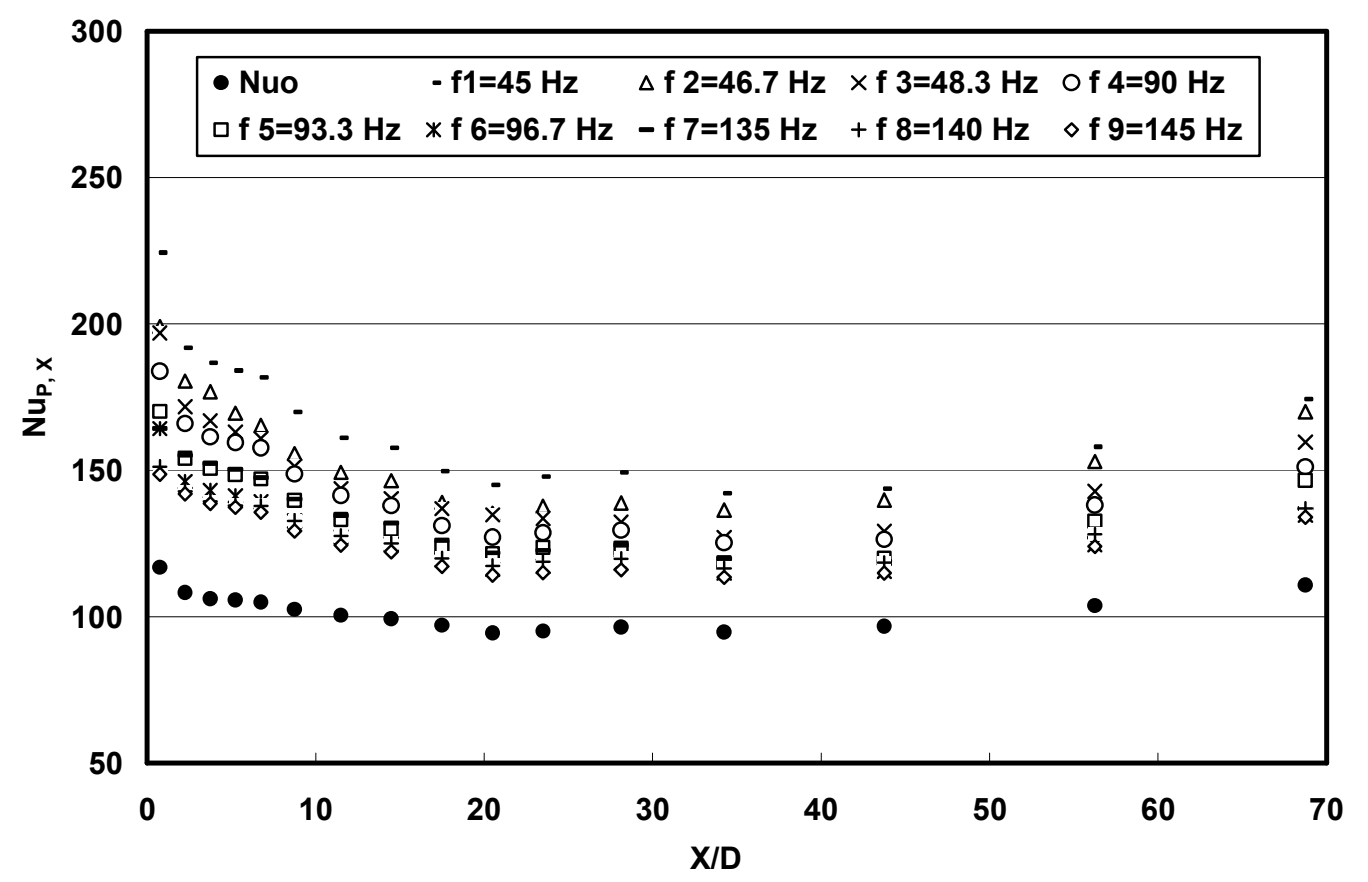

(a) $\operatorname{Re}=42500$

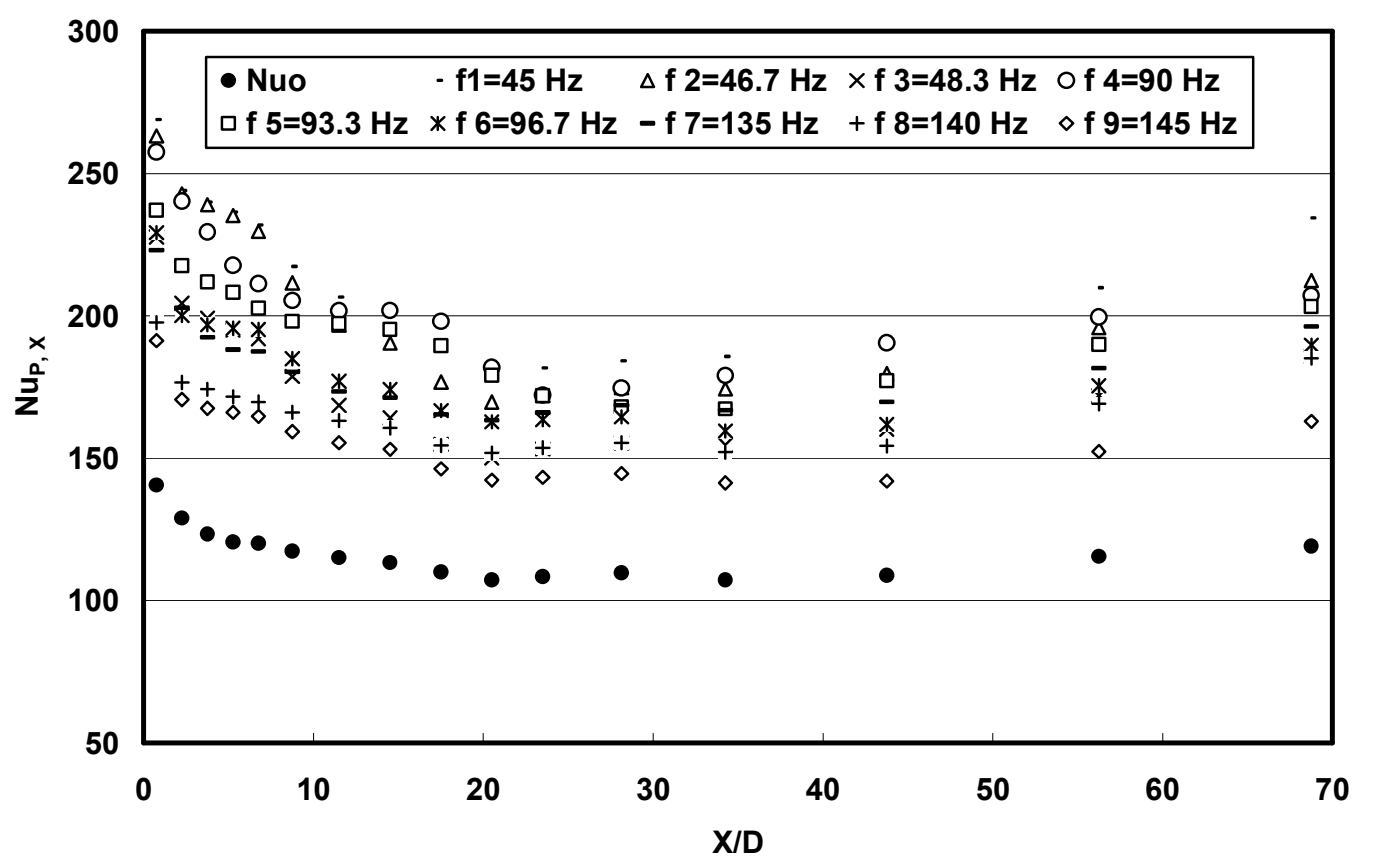

(b) $\mathrm{Re}=\mathbf{5 8 9 0 0}$

Fig.(4): Local Nusselt number at different flow pulsation frequencies. 


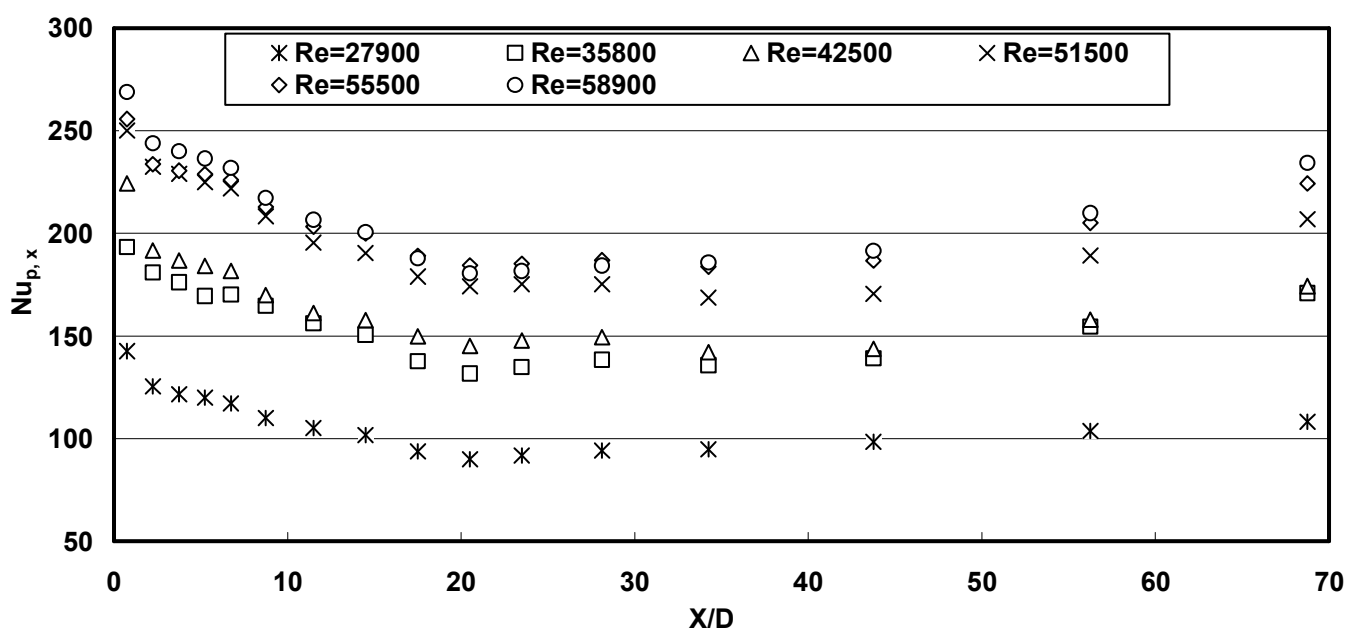

(a) $f=45 \mathrm{~Hz}$

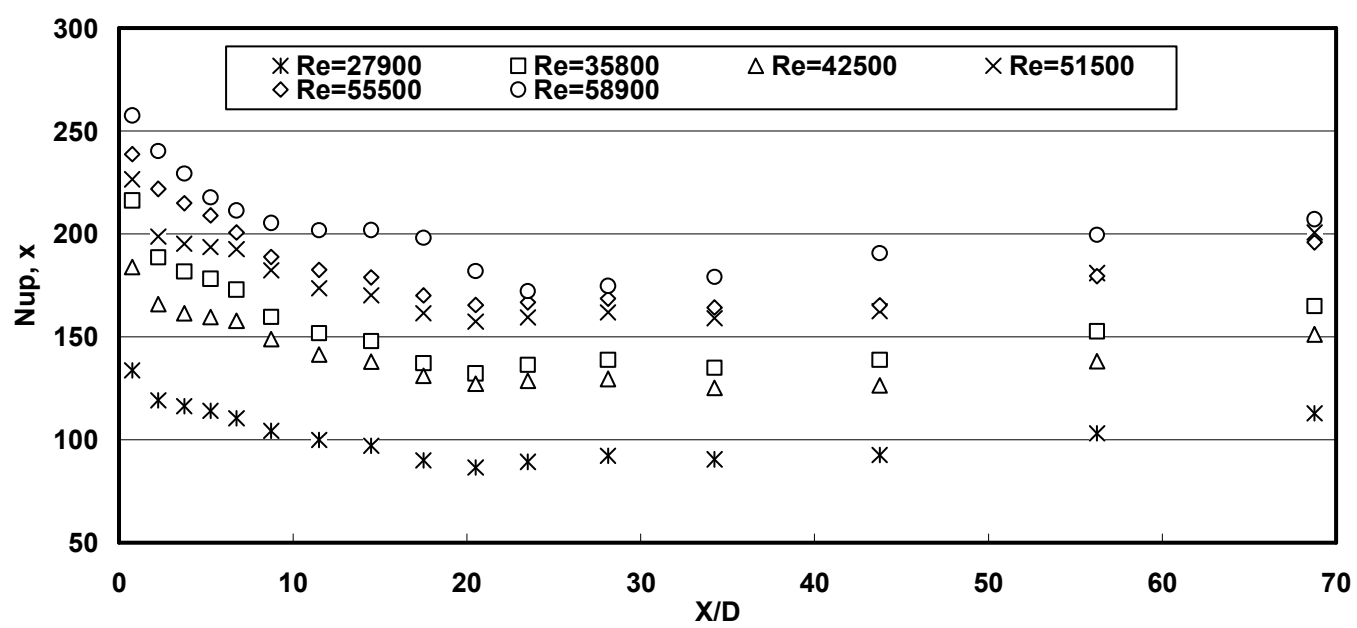

(b) $f=90 \mathrm{~Hz}$

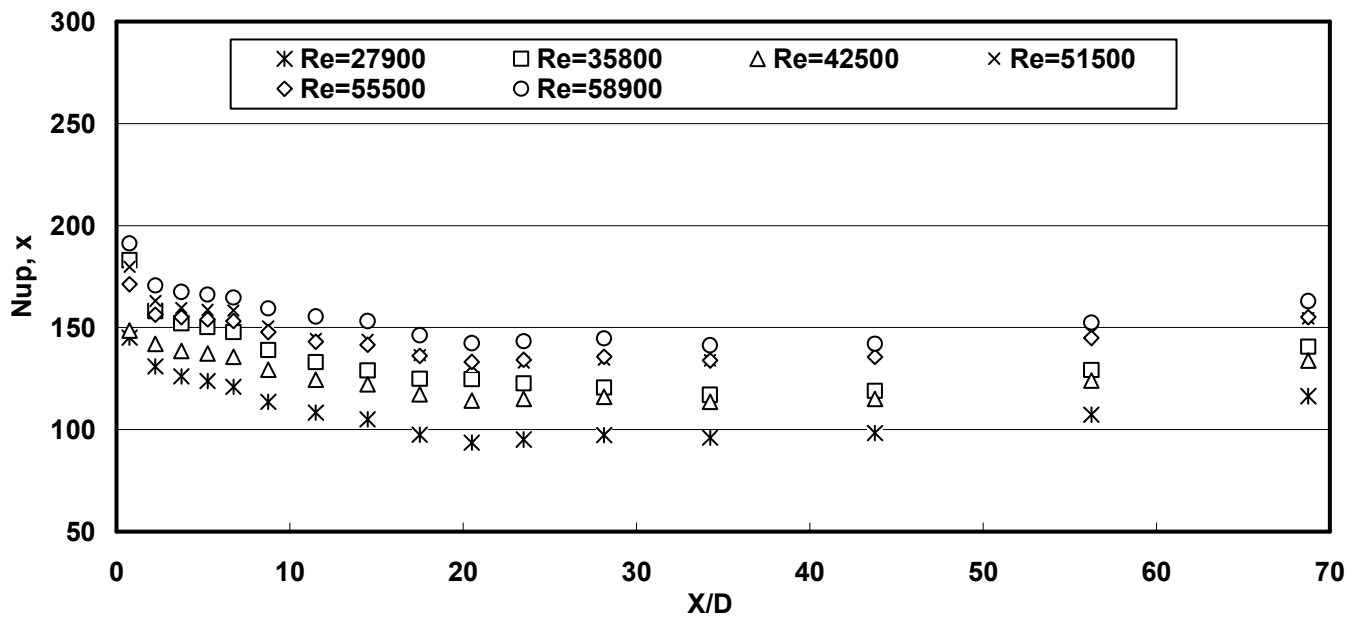

(c) $f=145 \mathrm{~Hz}$

Fig 5): Local Nusselt number at different Reynolds numbers for flow with different pulsation frequencies 


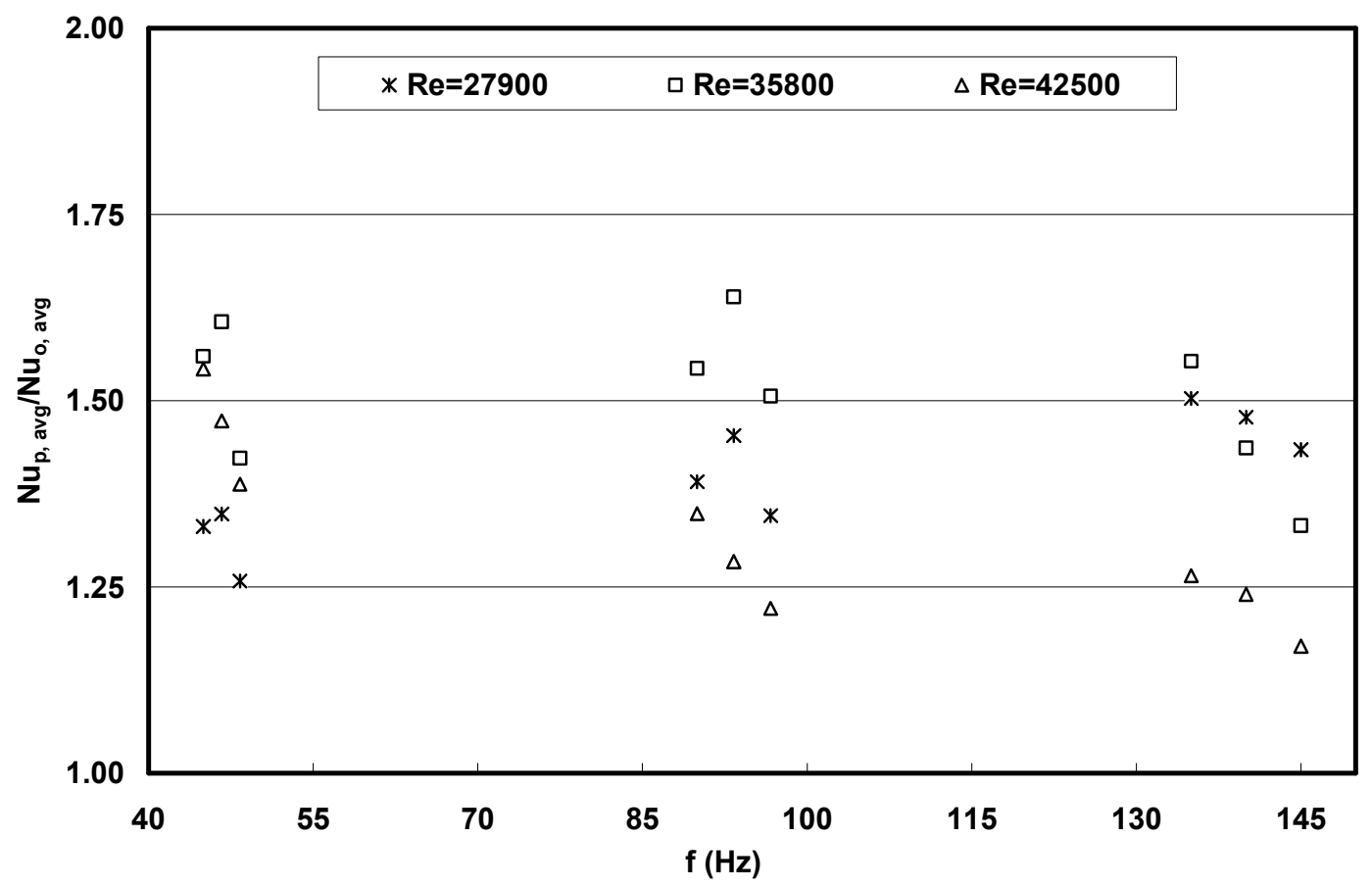

(a) $27900 \leq \operatorname{Re} \leq 42500$

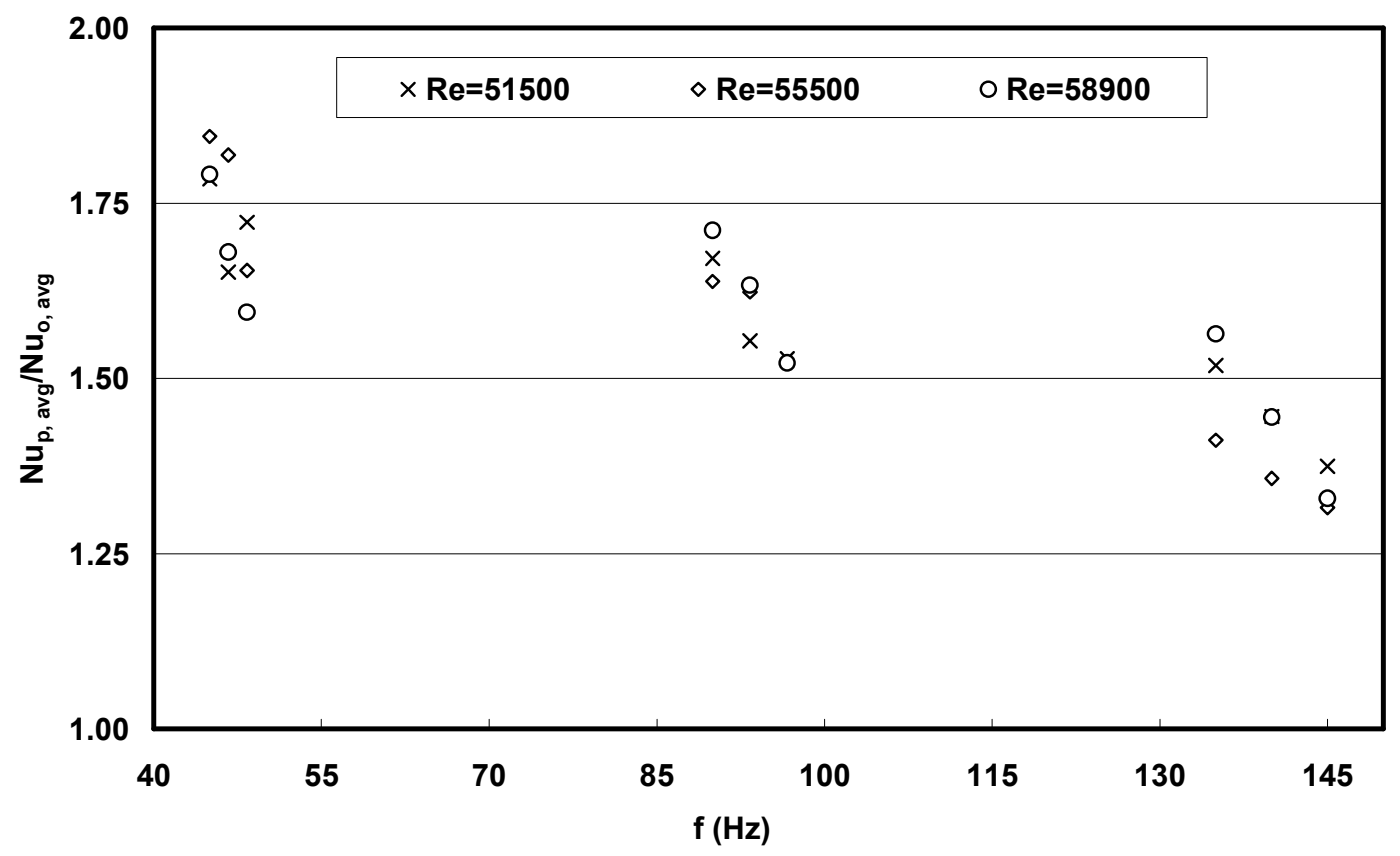

(b) $\mathbf{5 1 5 0 0} \leq \mathrm{Re} \leq \mathbf{5 8 9 0 0}$

Fig.(6): Relative average Nusselt number vs. frequencies at different Reynolds numbers. 


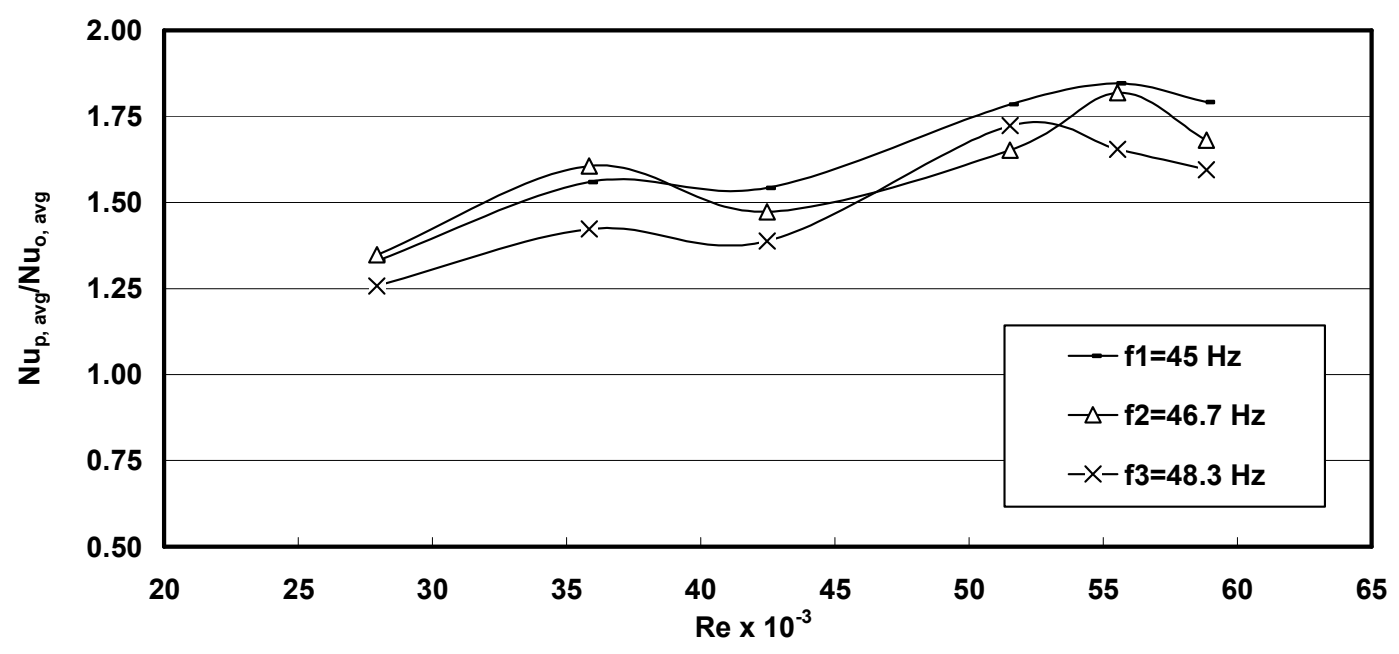

(a) $45 \leq f \leq 48.3 \mathrm{~Hz}$

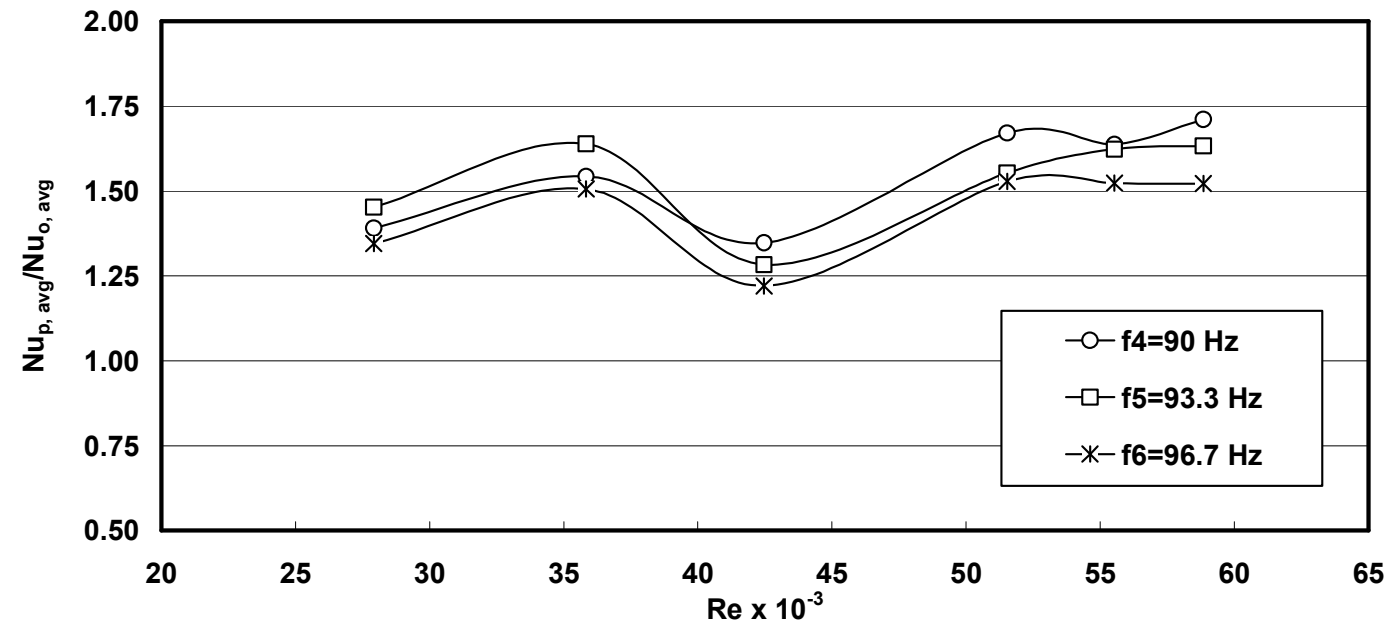

(b) $90 \leq f \leq 96.7 \mathrm{~Hz}$

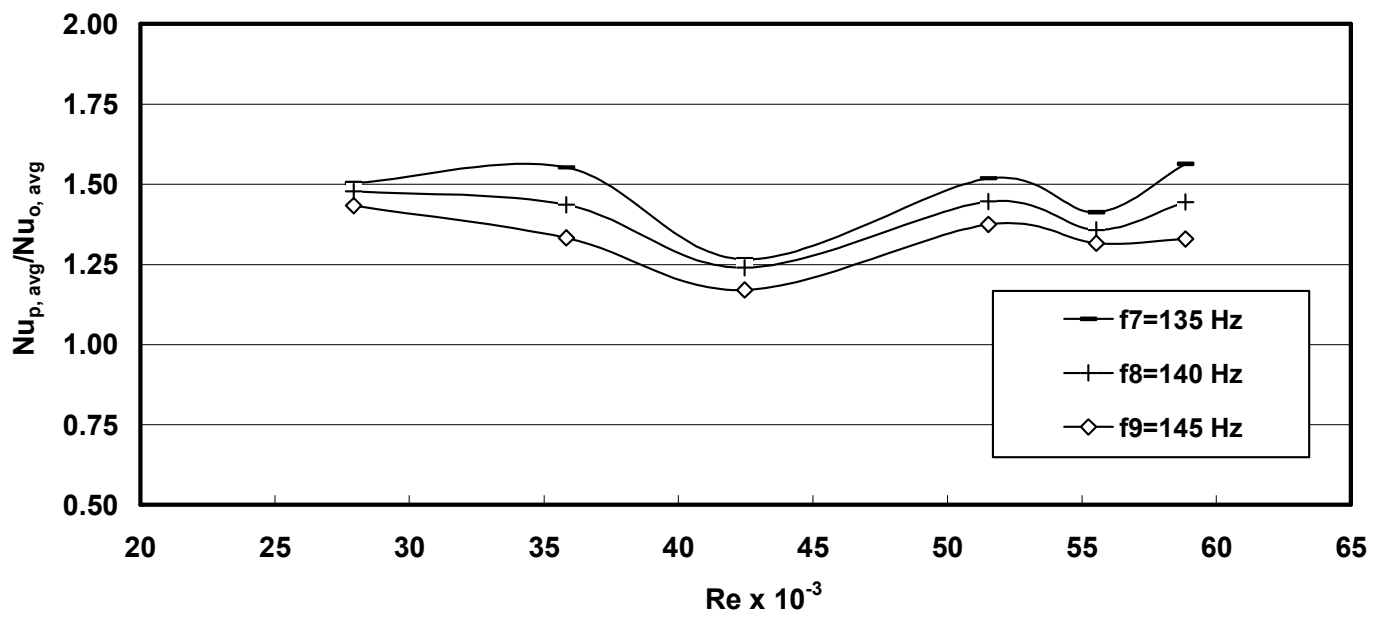

(c) $135 \leq f \leq 145 \mathrm{~Hz}$

Fig.(7): Relative average Nusselt number versus Reynolds numbers at different frequencies . 


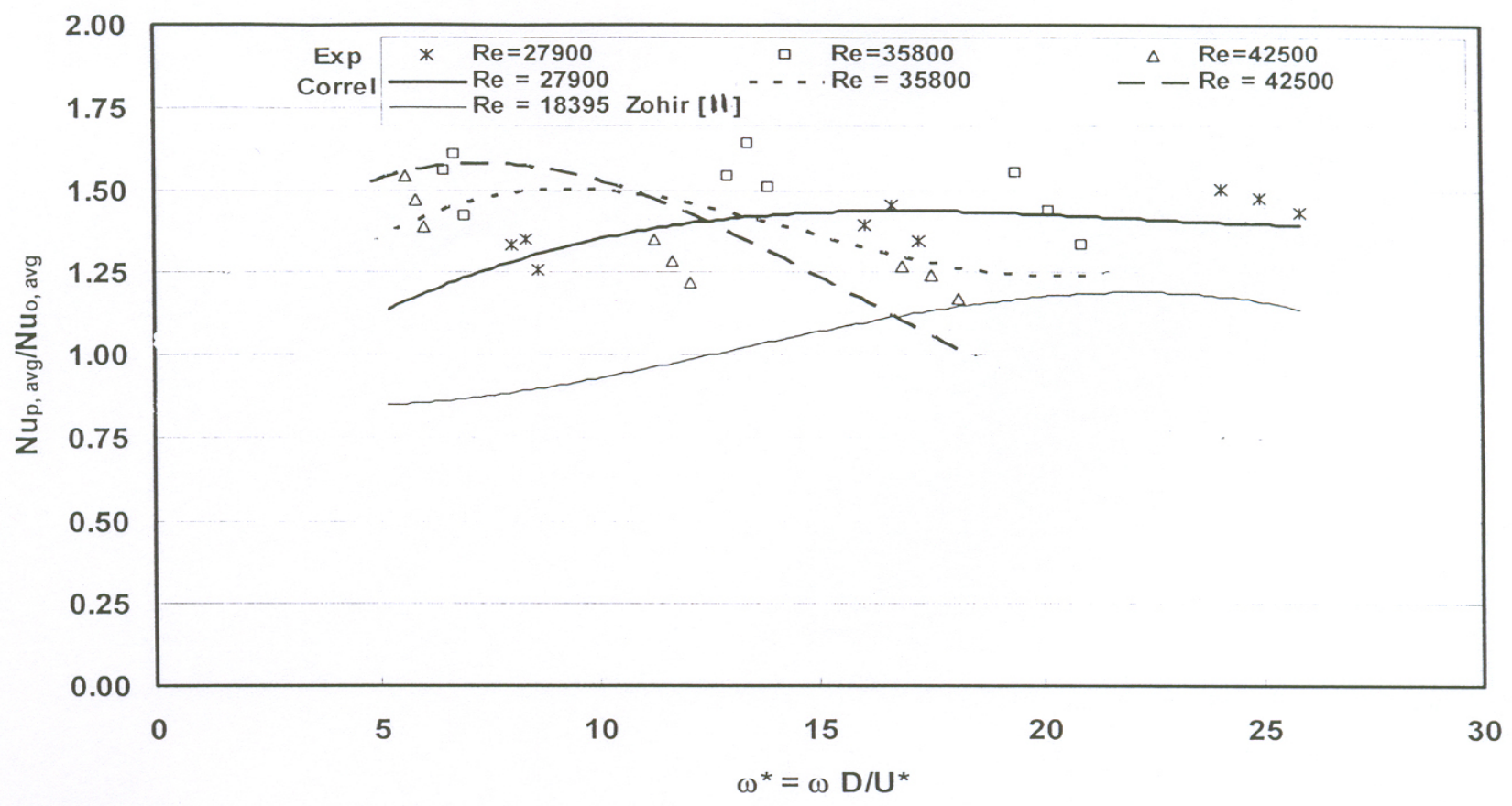

(a) $(27900 \leq \operatorname{Re} \leq 42500)$

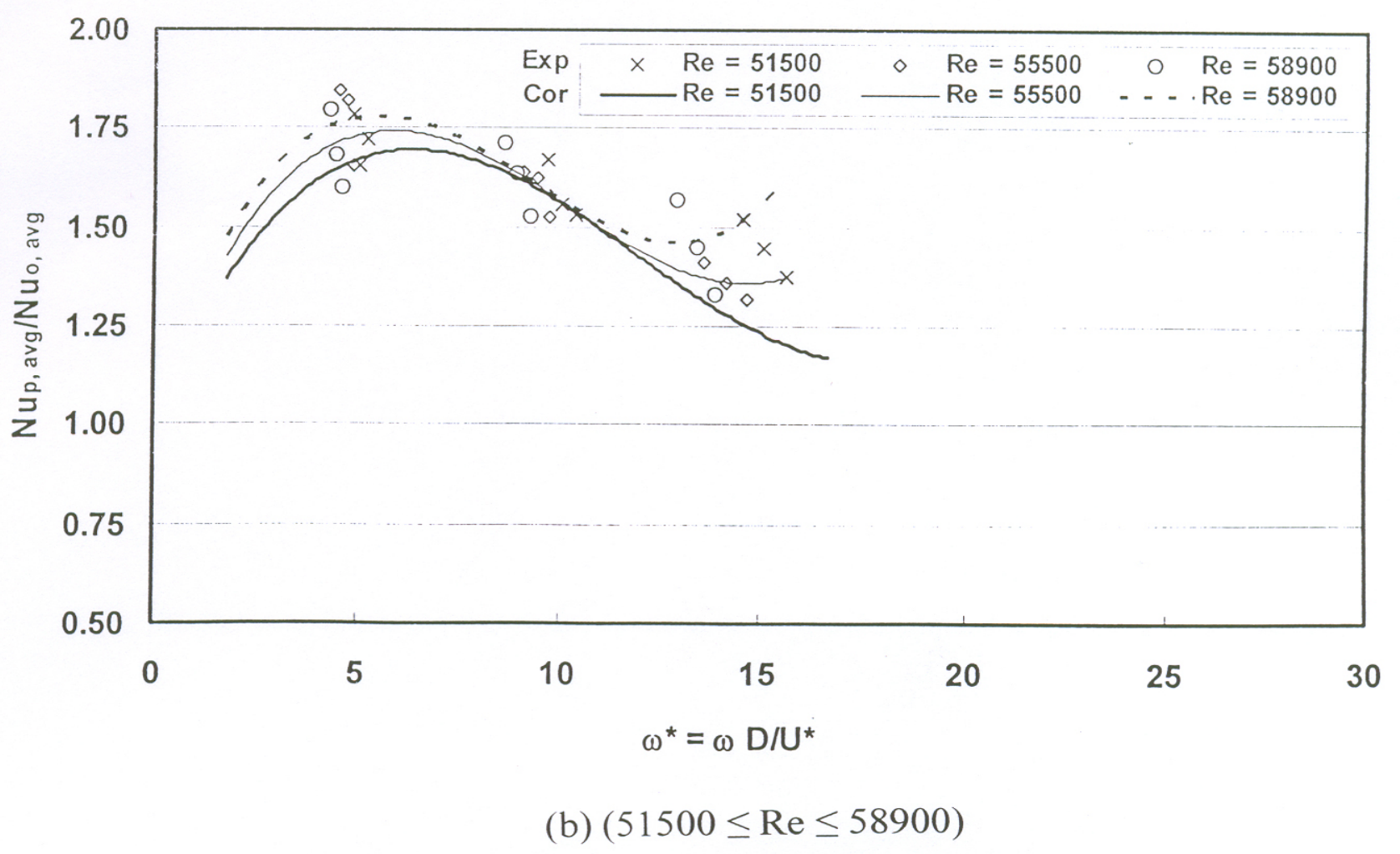

Fig. (8):Comparison between the present correlation and the experimental data 